\title{
Hemşirelerin Basınç Ülserlerini Önlemeye Yönelik Tutumlarının İncelenmesi
}

\author{
Cansu ERCAN EKİM* ${ }^{*}$ Necmiye SABUNCU**
}

\section{$\ddot{O} \mathbf{z}$}

Amaç: Araştırma hemşirelerin basınç ülserlerini önlemeye yönelik tutumlarını ölçmek amacıyla tanımlayıcı olarak yapılmıştır.

Yöntem: Araştırmanın örneklemini Kasım 2017-Ocak 2018 tarihleri arasında İstanbul'da özel bir sağlık kuruluşunda çalışan, araştırma kriterlerine uyan ve araştırmaya katılmayı kabul eden 131 hemşire oluşturdu. "Basınç Ülserlerini Önlemeye Yönelik Tutum Ölçeği” (BÜÖYTÖ) uygulandı. Çalışmada veriler IBM SPSS Statistics 24 (IBM SPSS, Türkiye) programı kullanılarak analiz edildi. Tanımlayıcı istatistiksel metotlar (Frekans, Yüzde, Ortalama, Standart sapma), Kolmogorov-Smirnov dağılım testi, Mann Whitney U testi, Kruskal Wallis testi ve Spearman Korelasyon Analizi kullanıldı.

Bulgular: Hemşirelerin BÜÖYTÖ puan ortalaması 44,69 $\pm 3,00 \quad(\% 85,9)$ saptanmıştır.

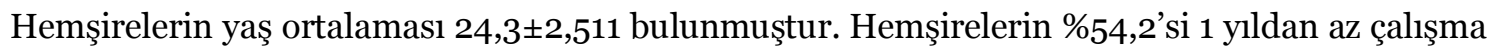
deneyimine sahip, \%42'si Cerrahi Servisiler, \%34,4 Dahili Servisler, \%27,7'si Yoğun Bakımlarda çalışmaktadır. Hemşirelerin sosyodemografik özellikleri ile BÜÖYTÖ puanları arasındaki ilişki istatistiksel açıdan anlamlı bulunmamıştır ( $>00,05)$. Basınç ülseri ile her zaman karşılaşan hemşirelerin BÜÖYTÖ puanlarının daha yüksek olduğu saptanmıştır ( $\mathrm{p}<0,05)$.

Sonuç: Hemşirelerin basınç ülserlerini önlemeye yönelik tutumlarının yüksek olduğu ve basınç ülseri ile her zaman karşılaşanların tutumunun daha olumlu olduğu saptandı.

Anahtar Sözcükler: Basınç ülseri önleme, tutum, hemşirelik.

\footnotetext{
Özgün Araştırma Makalesi (Original Research Article)

Geliş / Received: 18.06.2019 \& Kabul / Accepted: 17.09.2019

${ }^{*}$ Uzm. Hemşire, Koç Üniversitesi Hastanesi, İstanbul, Türkiye,

E-posta: cansuercan2@gmail.com ORCID ID https://orcid.org/oooo-0002-0750-9673

** Prof. Dr., Haliç Üniversitesi, Hemşirelik Yüksekokulu, İstanbul, Türkiye,

E-posta: necmiyesabuncu@halic.edu.tr ORCID ID https://orcid.org/o0o0-0003-0643-9922
} 


\title{
Examination of Nurses' Attitudes Towards Prevention of Pressure Ulcers
}

\begin{abstract}
Aim: The study was designed as a descriptive study to determine the attitudes of nurses to prevent pressure ulcers.

Method: The sample of the study consisted of 131 nurses working in a private hospital in Istanbul between November 2017 and January 2018, who agreed with the research criteria and agreed to participate in the research. "Attitude Towards Pressure Ulcer Prevention Instrument" (APuP) was applied. The data were analyzed using the program of IBM SPSS Statistics 24 (IBM SPSS, Turkey). When the data were evaluated in the study, descriptive statistical methods (Frequency, Percentage, Mean, Standard deviation), Kolmogorov - Smirnov distribution test, Mann Whitney U test, Kruskal Wallis test and Spearman correlation analysis were used for statistical analysis.
\end{abstract}

Findings: The nurses' average score on the Attitude towards Pressure Ulcer Prevention Instrument was $44,69 \pm 3,00(\% 85,9)$. The avarage age of the nurses was $24,3 \pm 2,51.54,2 \%$ of nurses had working experience less than 1 year. The working areas of nurses in the study were 42\% Surgical Services, 34,4\% Internal Services, and 27,7\% Intensive Care. The relationship between sociodemographic characteristics of nurses and Attitudes Towards Pressure Ulcer Prevention Instrument scale scores was not statistically significant ( $p>0,05)$. It was found that the Attitudes Towards Pressure Ulcer Prevention Instrument scale scores of the nurses who always met with the pressure ulcer were higher $(\mathrm{p}<0,05)$.

Conclusion: It was seen that the nurses' attitudes towards pressure ulcer prevention was high and nurses who always encountered the pressure ulcer had more positive attitude.

Keywords: Pressure ulcer prevention, attitude, nursing.

\section{Giriș}

Basınç ülserleri gelişen teknoloji, yeni tıbbi cihazlar ve sürekli eğitimler ile önlenebilir olmasına rağmen dünyada ve ülkemizde hem hastalar hem de sağlık çalışanları üzerinde önemli ölçüde yük oluşturmaya devam etmektedirir-3. Health Grades’in (2011) hasta güvenliği raporunda Amerika'da bir yıl içinde hastaneye yatışı yapılan hastalarda basınç ülseri gelişme insidansının \%2,7 olduğu görülmüştür. Bu ülserlerin sağllk harcamalarına yansımasının ise 2 milyar dolar'ı bulduğu rapor edilmiştir4. Yapılmış diğer çalışmalar incelendiğinde basınç ülserlerinin görülme prevalansı Avrupa 
ülkelerinde \%9-18 arasında değişmekte olduğu bulunmuştur5. Ülkemizde yapılan çalışmalar incelendiğinde genel prevelansın \%2,5-\%8,11 arasında değiştiği görülmektedir6,7.

Basınç ülserleriyle mücadele her ne kadar multidisipliner bir yaklaşım gerektirse de basınç ülserlerini önlemede hemşirelik bakımı her zaman ön planda olmuştur ve 1980'lerden beri yetersiz bakımın göstergesi olarak sunulmaktadır ${ }^{8}$. Basınç ülserlerini önleme ve bakımında hemşirenin bilgi düzeyi ve klinik becerisi kadar basınç ülserlerine yönelik tutumları da önemlidir. Çünkü tutumlar, bir bireyin faaliyetlerinin ve performansının arkasındaki ana itici güç veya motivasyondur. Yani karar verme sürecine yardımcı olurlar ve eylemlerinin mükemmellik seviyesini belirlerler ${ }^{9,10}$. Hemşirenin yeni bilgileri klinik uygulamaya koyma isteği, basınç ülserini önlemeye yönelik tutumu, yeterli ekipman desteği ve ekip çalışması bu süreci yönetmek için gerekli bileşenlerdir ${ }^{11}$. Bu nedenle hemşirelerin sadece bilgi düzeyi değil, basınç ülserlerini önlemeye yönelik tutumları oldukça önemlidir.

Basınç ülserlerine karşı hemşire tutumlarını belirlemeye yönelik çalışmalar sonucunda Beeckman ve ark. bir ölçek geliştirmiş ve Üstün ve ark. bu ölçeğin Türkçe geçerlilik ve güvenirliğini çalışmıştır ${ }^{12,13}$. Aslan ve Giersbergen’in hemşirelerin basınç yarasını önlemeye yönelik tutumlarını araştıran çalışmasında basınç yarası ile ilgili klavuzları okumanın ve alınan eğitimlerin hemşirelerin tutumlarını olumlu yönde etkilediği görülmüştür ${ }^{11}$. Bir başka araştırmada ise katılımcıların basınç ülseri bilgi puan ortalamalarının \%71.5 olmasına rağmen tutum puanlarının tatmin edici düzeyde olmadığı görülmüştüri14.

Basınç ülserleri hasta, hastane ve sağlık hizmeti sunucularına getirdiği yükler açısından incelendiğinde tüm dünyada olduğu gibi ülkemizde de önemli bir sorundur. Basınç ülserlerinin önlenmesinde hemşireler kilit roldedir. Bu nedenle hemşirelerin basınç ülserlerini önlemeye yönelik tutumlarının incelenmesi önemlidir.

\section{Gereç ve Yöntem}

Araştırma İstanbul'da özel bir hastanede Kasım 2017 - Ocak 2018 tarihleri arasında yapılmıştır. Araştırmanın evrenini yatan hastalara bakım veren cerrahi servisiler, dahiliye servisleri ve yoğun bakımlarda çalışan hemşireler oluşturmuştur. Araştırmada örneklemi "Braden Bası Yarası Risk Tanılama Ölçeği” puanı 16 ve altı, yani basınç 
yarası riski olan hastalara bakım veren ve çalışma süresi en az 2 ay olan hemşireler oluşturmuştur. Yapılan istatistiksel inceleme sonucunda örneklem 131 hemşire olarak belirlenmiştir. Araştırmada veriler hemşirelerin basınç ülserlerini önlemeye yönelik tutumlarını incelemek amacıyla 14 sorudan oluşan Hemşire Tanıtım Formu ve 13 sorudan oluşan Basınç Ülserlerini Önlemeye Yönelik Tutum Ölçeği kullanılarak toplanmıştır.

\section{Hemşire Tanıtım Formu}

Form araştırmaya katılan hemşirelerin sosyo-demografik ve basınç ülserlerine yönelik tanıtıcı bilgilerini içeren 14 sorudan oluşmaktadır.

\section{Basınç Ülserlerini Önlemeye Yönelik Tutum Ölçeği (BÜÖYTÖ)}

Hemşirelerin basınç ülserlerini önlemeye yönelik tutumlarını belirlemek amacıyla Beeckman ve ark. tarafından geliştirilen ölçek Belçika ve Hollanda'da 258 hemşire ve 291 hemşirelik öğrencisine uygulanmıştır ${ }^{12}$. Geçerli ve güvenilir bir ölçek olduğu bulunmuştur. Ölçeğin iç tutarlılığın güvenirliği Cronbach Alpha değeri; 0,79 olarak bulunmuştur.

Ölçeğin Türkçe uyarlaması Üstün ${ }^{13}$ tarafından yapılmış, 171 hemşireye uygulanan ölçeğin iç güvenirliği Cronbach Alpha değeri o,714 bulunmuştur. BÜÖYTÖ 5 alt boyutta toplam 13 madde içermektedir. Ölçeğin alt boyutları; basınç ülserlerini önlemek için bireysel yeterliliğe yönelik tutum (3 madde), basınç ülserlerini önleme önceliğine yönelik tutum (3 madde), basınç ülserlerinin etkisine yönelik tutum (3 madde), basınç ülserlerini önlemede kişisel sorumluluğa yönelik tutum ( 2 madde), basınç ülserlerini önlemenin etkinliğine yönelik tutum ( 2 madde) olmak üzere toplam 13 maddedir. BÜÖYTÖ’nin toplam puan ortalamaları yükseldikçe tutumun olumlu olması beklenmektedir. Veriler yüzyüze görüşme tekniği ile toplandı. Anketlerin uygulanması her bir katılımcı için 10 dakika sürmüştür.

\section{Verilerin Değerlendirilmesi}

Çalışmada elde edilen bulgular değerlendirilirken, istatistiksel analizler için SPSS 24.0 İstatistik paket programı kullanılmıştır. Çalışma verileri değerlendirilirken tanımlayıcı istatistiksel metotların (Frekans, Yüzde, Ortalama, Standart sapma) yanı sıra normal dağılımın incelenmesi için Kolmogorov-Smirnov dağılım testi kullanılmıştır. Veriler normal dağılıma sahip olmadığı için parametrik olmayan yöntemlerden Mann Whitney 
U test, Kruskal Wallis testi ve Spearman Korelasyon Analizi kullanılmıştır. Sonuçlar \% 95 güven aralığında, $\mathrm{p}<0,05$ anlamlılık düzeyinde değerlendirilmiştir.

\section{Araştırmanın Etiği}

Araştırmanın ilgili kurumda yürütülebilmesi için Koç Üniversitesi Sosyal Bilimler Araştırmaları Etik Kurulu'ndan 15.11.2017 tarihinde 2017.007.IRB3.003 nolu izin yazısı ile araştırmanın yapılacağı kurumdan anket çalışma izni alınmıştır. Araştırma süresince hemşirelere araştırmanın amacı açıklanarak çalışmaya gönüllü olarak katılmaları sağlanmıştır.

\section{Bulgular}

Katılımcların kişisel özelliklerine ilişkin bulgular Tablo 1'de gösterildiği gibi \%92,4’ü kadın, \%7,6'sı erkek; \%94,7'si lisans eğitim seviyesindedir. Hemşirelerin yaş ortalaması $24,3 \pm 2,511$ saptanmıştır. Hemşirelerin \%42'si cerrahi servisilerde, \%34,4 dahili servisler, \%27,7 yoğun bakımlarda çalışmaktadır. Hemşirelerin \%54,2'sinin 1 yıldan az deneyime sahip olduğu, \%54,2'sinin mezuniyetinden sonra basınç ülserlerinin önlenmesi/bakımına yönelik eğitim aldığı, \%52,7'sinin bir ayda ortalama 1-3 hastaya basınç ülseri bakımı yaptığı saptanmıştır. Hemşirelerin \%27,5’i nadiren, \%61,1’i sık sık, \%11,5’i her zaman basınç ülserli hasta ile karşlaştığını belirtmiştir.

Hemşirelerin toplam tutum puanları ortalamalarının basınç ülseri olan hasta ile karşılaşma sıklığı değişkeni açısından anlamlı bir farklılık gösterip göstermediğini belirlemek amacıyla yapılan Kruskal Wallis H-Testi sonuçlarına göre; grup ortalamaları arasındaki fark anlamlı bulunmuştur (KW=8,931; p=0,012<0.05). Farklılığın hangi gruptan kaynaklandığını belirlemek üzere yapılan Mann Whitney U testine göre; basınç ülseri olan hasta ile karşılaşma sıklığı "Her zaman” olanların toplam tutum puanları $(47,00 \pm 2,75)$, "Nadiren" olanların toplam tutum puanlarından $(44,64 \pm 2,67)$ ve "Sik sıl" olanların toplam tutum puanlarından $(44,28 \pm 3,02)$ yüksek bulunmuştur $(\mathrm{p}<0,05)$. 
Tablo 1. Hemşirelerin Kişisel Özelliklerinin Dağılımına göre BÜÖYTÖ Puan Ortalamalari $(\mathbf{n}=\mathbf{1 3 1})$

\begin{tabular}{|c|c|c|c|c|}
\hline & & n (\%) & Ort \pm Ss & $P$ değeri MW/KW \\
\hline Cinsiyet & $\begin{array}{l}\text { Kadın } \\
\text { Erkek }\end{array}$ & $\begin{array}{l}121(92,4) \\
10(7,6)\end{array}$ & $\begin{array}{l}44,65 \pm 3,02 \\
45,10 \pm 2,85\end{array}$ & $\begin{array}{l}\text { p: } 0,679 \\
\text { MW: } 557,5\end{array}$ \\
\hline $\begin{array}{l}\text { En Son Tamamladığı } \\
\text { Hemşirelik Programı }\end{array}$ & $\begin{array}{l}\text { Lise } \\
\text { Lisans } \\
\text { Lisansüstü }\end{array}$ & $\begin{array}{l}3(2,3) \\
124(94,7) \\
4(3,1)\end{array}$ & $\begin{array}{l}46,00 \pm 2,65 \\
44,67 \pm 3,05 \\
44,25 \pm 1,71\end{array}$ & $\begin{array}{l}\text { p: } 0,628 \\
\text { KW: } 0,932\end{array}$ \\
\hline Çalıştığı Bölüm & $\begin{array}{l}\text { Yoğun Bakımlar } \\
\text { Cerrahi Servisler } \\
\text { Dahili Servisler }\end{array}$ & $\begin{array}{l}31(23,7) \\
45(34,4) \\
55(42)\end{array}$ & $\begin{array}{l}44,46 \pm 3,96 \\
43,67 \pm 3,67 \\
45,50 \pm 2,90\end{array}$ & $\begin{array}{l}\text { p: } 0,604 \\
\text { KW: } 1,009\end{array}$ \\
\hline Çalışma Yılı & $\begin{array}{l}1 \text { yıldan az } \\
1-5 \text { yll } \\
5-10 \text { yll } \\
10 \text { yıldan fazla }\end{array}$ & $\begin{array}{l}71(54,2) \\
51(38,9) \\
7(5,3) \\
2(1,5)\end{array}$ & $\begin{array}{l}44,28 \pm 2,82 \\
45,14 \pm 3,11 \\
45,43 \pm 3,99 \\
45,00 \pm 2,83\end{array}$ & $\begin{array}{l}\text { p: } 0,381 \\
\text { KW: } 3,067\end{array}$ \\
\hline $\begin{array}{l}\text { Mezuniyet Sonrası Basınç } \\
\text { Ülseri Önlenme/Bakıma } \\
\text { Yönelik Bir Eğitim Alma }\end{array}$ & $\begin{array}{l}\text { Evet } \\
\text { Hayır }\end{array}$ & $\begin{array}{l}71(54,2) \\
60(45,8)\end{array}$ & $\begin{array}{l}44,87 \pm 2,98 \\
44,47 \pm 3,04\end{array}$ & $\begin{array}{l}\text { p: o,336 } \\
\text { MW: } 1923\end{array}$ \\
\hline $\begin{array}{l}\text { Basınç Ülseri Olan Hasta } \\
\text { ile Karşılaşma Sıklığı }\end{array}$ & $\begin{array}{l}\text { Nadiren } \\
\text { Sik Sık } \\
\text { Her Zaman }\end{array}$ & $\begin{array}{l}36(27,5) \\
80(61,1) \\
15(11,5)\end{array}$ & $\begin{array}{l}44,64 \pm 2,67 \\
44,28 \pm 3,02 \\
47,00 \pm 2,75\end{array}$ & $\begin{array}{l}\text { p: o, } \mathbf{o 1 2}^{*} \\
\text { KW: } 8,931\end{array}$ \\
\hline $\begin{array}{l}\text { Bir Ayda Basınç Ülseri } \\
\text { Bakımı Yapılan Ortalama } \\
\text { Hasta Sayısı }\end{array}$ & $\begin{array}{l}\text { Hiç } \\
\text { 1-3 hasta } \\
\text { 4-6 hasta } \\
7 \text { ve üzeri hasta }\end{array}$ & $\begin{array}{l}2(1,5) \\
69(52,7) \\
38(29) \\
22(16,8)\end{array}$ & $\begin{array}{l}47,50 \pm 0,71 \\
44,10 \pm 3,05 \\
45,11 \pm 2,71 \\
45,55 \pm 3,11\end{array}$ & $\begin{array}{l}\text { p: } 0,077 \\
\text { KW: } 6,85\end{array}$ \\
\hline
\end{tabular}

KW: Kruskal Wallis - H Testi; MW: Mann-Whitney U Test; * $p<0,05$

Hemşirelerin BÜÖYTÖ ilişkin sonuçları Tablo 2'de gösterildiği gibi ölçek toplam puan ortalaması $(44,69 \pm 3,00)$ 'dır. Alt boyutlara baktığımızda "yeterlilik boyutu” ortalaması $(8,78 \pm 1,23)$; “öncelik boyutu” ortalaması $(10,55 \pm 1,01)$; “etki boyutu” ortalaması 


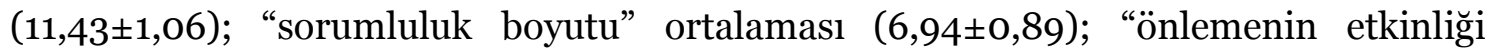
boyutu” ortalaması $(6,99 \pm 0,87)$ olarak saptanmıştır. Ölçekten alınabilecek maksimum puan 52'dir. Buna göre alınan puanların ortalaması 100 üzerinden hesaplandı̆̆ında toplam tutum puanı \%85,9, yeterlilik boyutu puanı \%73,2, öncelik boyutu puanı \%87,9, etki boyutu puanı, \%95,2, sorumluluk boyutu puanı \%86,7, önlemenin etkinliği boyutu puanı \%87,4 bulunmuştur.

Tablo 2. Hemşirelerin Basınç Ülserlerini Önlemeye Yönelik Tutumlarına İlişkin Tanımsal Bulgular $(\mathbf{n = 1 3 1})$

\begin{tabular}{|l|l|l|l|l|l|l|}
\hline & $\mathbf{n}$ & Ort & Ort (\%) & Ss & Min. & Maks. \\
\hline Toplam Tutum & 131 & 44,69 & 85,9 & 3,00 & 37 & 51 \\
\hline Yeterlilik boyutu & 131 & 8,78 & 73,2 & 1,23 & 6 & 12 \\
\hline Öncelik boyutu & 131 & 10,55 & 87,9 & 1,01 & 8 & 12 \\
\hline Etki boyutu & 131 & 11,43 & 95,2 & 1,06 & 8 & 12 \\
\hline Sorumluluk boyutu & 131 & 6,94 & 86,7 & 0,89 & 4 & 8 \\
\hline Önlemenin etkinliği boyutu & 131 & 6,99 & 87,4 & 0,87 & 4 & 8 \\
\hline
\end{tabular}

\section{Tartışma}

“Basınç Ülserini Önlemeye Yönelik Tutum Ölçeği” puan ortalamaları yüzdelik incelendiğinde toplam puan ortalaması \%85,9 bulunmuştur. Literatürde hemşirelerin basınç yarasını önlemeye yönelik tutumlarını inceleyen diğer çalışmalarla karşılaştırıldığında çalışmamızda hemşirelerin tutum puanlarının yüksek olduğu görülmüştür. $\mathrm{Bu}$ yüksekliğin araştırmanın yapıldığı, hemşirelik mesleğinde uygulamalara, araştırmalara, eğitime ve bilgi birikimine büyük destek veren bir gelenekten gelen, kurum ile ilişkili olduğu düşünülmüştür. Üstün, çalışmasında

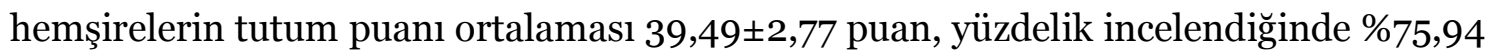
puan ortalamasının tutumun olumlu olduğu şeklinde yorumlamıştır ${ }^{13}$. Literatürdeki diğer araştırmalar incelendiğinde "Basınç Ülserini Önlemeye Yönelik Tutum Ölçeği” tutum puan ortalamaları Belçika'daki hemşireler ile yapılan Beeckman ve ark.'nın15 çalışmasında \%71,3 (37,1), Aslan ve Yavuz van Giersbergen'ın'11 çalışmasında \%84,12 
(43,74 44,29), Demarre ve ark.'nın ${ }^{16}$ Belçika'da bakım evlerinde çalışan 145 hemşire ile yaptığı çalışmada \%74,5, Ünver ve ark. ${ }^{17}$ çalışmasında \%80,59 bulunmuştur. Basınç ülserini önlemeye yönelik tutumu ölçen çalışmalar hemşirelik öğrencileri ile de yapılmıştır. Buna göre; Avusturalya'da 7 üniversitenin toplam 2949 hemşirelik öğrencisinin katılımıyla yapılan Usher ve ark. (2018) çalışmasında tutum puanı \%78,46 (40,8 $\pm 3,9)$, İtalya'da 742 hemşirelik öğrencileri ile yapılan Simonetti ve ark. çalışmasında tutum puanı 76,7\% $(39,9)$ bulunmuştur ${ }^{18,19}$. Hemşirelerin "Basınç Ülserini Önlemeye Yönelik Tutum Ölçeği” alt boyutlarının puanları incelendiğinde hemşirelerin en yüksek puanı "Etki boyutu"ndan aldığı, en düşük puanı ise "Yeterlilik Boyutundan" aldığı saptanmıştır (Tablo 2). Bulguların Aslan ve van Giersbergen ve Üstün’ün araştırmaları ile uyumlu olduğu görülmüştür ${ }^{11,13}$. Kişisel yeterliliğe yönelik tutum puan ortalamasının düşük bulunması, hemşirelerin aldıkları eğitimi bakımına yansıtamaması ile ilişkili olarak yorumlanabilir. Basınç yaralanmasının önlenmesi ile ilgili yeterliliğin düşük olduğu hemşirelik öğrencileri ile gerçekleştirilen Usher ve Simonetti ve ark. çalışmaları ile de desteklenmektedir ${ }^{18,19}$. Çalışmalarda hemşire adaylarının, basınç yaralanmasını önlemek için yeteneklerine veya eğitimlerine güven duymadıkları gösterilmiştir. İsveç'te Athlin ve ark tarafından hemşirelerin $(\mathrm{n}=30)$ basınç ülserini önleme ve bakımını etkileyen değişkenlere yönelik algılarını tanımlamak için derinlemesine bireysel görüşme yöntemi ile niteliksel bir çalışma gerçekleştirilmiştir. Araştırma sonucunda hemşireler arasında basınç ülserini önlemeye yönelik girişimlerin daha düşük olduğu, hemşirelerin mevcut hastalığın tedavisi ve hasta bakımı ile daha çok ilgilendiği bulunmuştur ${ }^{20}$. Hemşirelerin basınç ülseri olan hasta ile karşılaşma sıklığının \%27,5’i (n=36) nadiren, \%61,1’i (n=80) sık sık, \%11,5’i $(n=15)$ her zaman olduğu ve basınç ülseri ile "her zaman" karşılaşanların tutum puanlarının "sık sık" ve "nadiren” karşılaşanlara göre BÜÖYTÖ puanlarının daha yüksek olduğu saptanmıştır (Tablo 1). Basınç ülserli hasta ile her zaman karşılaşan hemşireler basınç ülseri tedavisinin, önlemeye göre daha yoğun iş gücü, daha çok maliyet ve hasta açısından da olumsuz sonuçları olduğunu bilmeleri nedeniyle basınç ülserini önlemeye yönelik tutumlarının olumlu olduğunun yansıması olarak düşünülebilir. Hemşirelerin tutum puan ortalamalarının cinsiyet, yaş, en son tamamladığı hemşirelik programı ve çalışma yılı ile ilişkili olmadığı bulundu. Yapılan çalışmalarda da bu değişkenlerin tutum ortalaması ile ilişkisi bulunmamıştır ${ }^{11,14,17}$. Bu durum hemşirelerin sosyo-demografik özelliklerinin basınç ülserini önlemeye yönelik 
tutum üzerine etkisinin olmadığını göstermektedir. Hemşirelerin toplam tutum puan ortalamaları ile mezuniyetinden sonra basınç ülserlerinin önlenmesi/bakımına yönelik bir eğitim alma değişkeni arasında anlamlı bir farklılık bulunmamıştır. Beeckman ve ark. ${ }^{15}$ Belçika hastanelerindeki 553 hemşire ile yaptığı çalışmada ortalama tutum puanlarının basınç ülseri eğitimi ile ilişkili olmadığını, ancak eğitim alanların bilgi puanlarının anlamlı düzeyde arttı̆̆ını bildirmişlerdir. Araştırmaya katılanların klinikte önlemeye yönelik performansları da gözlenmiştir. Bilgi puanı ile önleme performansı arasında da bir ilişki saptanmamıştır. Avustralya'da McCluskey ve Lovarini²1, hedeflenen eğitimlerin davranış üzerindeki etkisinin sınırlı olduğunu, ancak bireylerin bilgilerinin geliştirilebileceğini bulmuşlardır. Gunningberg çalışmasında İsveçli hemşirelerin basınç ülseri önleme konusunda eğitim programı almaları, klinik uygulamalarını değiştirmesi için cesaretlendirdiği görülmüştür ${ }^{22}$. Kalman ve Suserun araştırmasında basınç ülserini önleme ile ilgili alınan eğitimin bilgi düzeyini etkilediği bulunmuştur ${ }^{23}$. Eğitimin tutuma etkisinin zayıf olduğunu gösteren çalışmaların aksine basınç ülseri ile ilgili eğitimin tutumu olumlu yönde etkilediğini gösteren kanıtlar da mevcuttur ${ }^{11,17}$. Dört yoğun bakım ünitesinde yapılan bir çalışmada Strand ve ark. hemşirelerin basınç ülseri önleme ile ilgili tutumlarını ve bilgilerini değerlendirmiştir ${ }^{24}$. Araştırmacılar, daha yüksek eğitim düzeyine sahip hemşirelerin, basınç ülserinin önlenmesinde daha fazla ilgiye sahip olduklarını saptamıştır ( $\mathrm{p}=0.009)$. Hemşirelerin üçte birinden fazlası (\%38) çalışanların bilgi düzeylerini basınç ülserini önlemek için bir kolaylaştırıcı olarak tanımlamıştır. Athlinn²0 nitel yöntem ile yaptığı çalışmasında hemşirelerin basınç ülserini önlemeye yönelik bilgilerinin yeterli olduğu ancak bu bilgileri nadiren pratiğe yansıttıkları bulunmuştur. Bu, farklı sonuçların basınç yarasını önlemeye yönelik verilen eğitimin içeriği ile ilgili olabileceği düşünülmektedir. Eğitim eksikliğinin, basınç ülserlerini önlemenin bir engeli olduğu ancak tutumunu etkileyip etkilemediği konusu eğitim içerikleri incelenerek daha fazla araştırılmalıdır.

\section{Sonuç ve Öneriler}

Hemşirelerin Basınç Ülserini Önlemeye Yönelik Tutum Ölçeği puan ortalaması yüksek olduğu ve basınç ülseri ile her zaman karşılaşan hemşirelerin BÜÖYTÖ puanlarının daha yüksek olduğu saptanmıştır. Basınç ülseri ile ilgili verilen eğitimlerin önlemeye yönelik olumlu tutum geliştirme üzerine etkisinin gözden geçirilmesi, yapılan 
eğitimlerde basınç yarasının önlenmesi ile ilgili yayınlanan uluslararası klavuzların anlatılması ve dağıtılması da önerilmektedir.

\section{KAYNAKLAR}

1. National Pressure Ulcer Advisory Panel (NPUAP). NEW 2014 prevention and treatment of pressure ulcers: clinical practice guideline. Availbale from http://www.npuap.org/resources/educational-and-clinical-resources/preventionand-treatment-of-pressure-ulcers-clinical-practice-guideline. Erişim tarihi 12 Ocak 2018.

2. Waugh S. Attitudes of nurses toward pressure ulcer prevention: a literature review. Medsurg Nursing. 2014;23(5):350-357.

3. Tel H, Özden D, Çetin P. Yatağa bağımlı hastalarda basınç yarası gelişme riski ve hemşirelerin bu hastalara uyguladıkları önleyici bakım. Hemşirelikte Araştırma Geliştirme Dergisi. 2006;1:35-45.

4. HealthGrades patient safety in american hospitals study. https://www.hospitals.healthgrades.com/CPM/assets/File/HealthGradesPatientS afetyInAmericanHospitalsStudy2011.pdf Yayımlanma tarihi 2011. Erişim tarihi 15 Kasım 2017.

5. Florin J, Baath C, Gunningberh L, Martensson G. Attitutes toward pressure ulcer prevention: a psychometric evalution of the swedish version of the APuP instrument. International Wound Journal. 2016;13(5):655-662.

6. Gencer ZE, Özkan Ö. Basınç ülserleri sürveyans raporu. Türk Yoğun Bakım Dergisi. 2015;13:26-30.

7. Aydın Karabağ A. Hemşirelerin Derin Doku Hasarı ve 1. Evre Basınç Ülserlerinin Bakımına İlişkin Uygulamalarının Belirlenmesi. [yüksek lisans tezi]. Ankara, Türkiye: Hemşirelik Anabilim Dalı, Gazi Üniversitesi Sağlık Bilimleri Enstitüsü;2008.

8. Lyder C, Ayello A. Pressure ulcer care and public policy: exploring the past to inform the future. Advances in Skin\&Wound Care Journal. 2012;25(2):72-77. 
9. Gill EC, Moore Z. An exploration of forth-year undergraduate nurses' knowledge of and attitude towards pressure ulcer prevention. Journal of Wound Care. 2013;22(11):618-625.

10. Allport GW. Attitudes. In: Murchison C, Worcester MA, eds. Handbook of Social Psychology. Clark University Press; 1935:810-820.

11. Aslan A, Van Giersbergen M. Nurses' attitudes towards pressure ulcer prevention in Turkey. Journal of Tissue Viability. 2016;25:66-73.

12.Beeckman D, Defloor T, Demarré L, Van Hecke A, Vanderwee K. Pressure ulcers: development and psychometric evaluation of the attitude towards pressure ulcer prevention instrument (APuP). International Journal of Nursing Studies. 2010;47:1432-1441.

13.Üstün Y. Basınç Ülserlerini Önlemeye Yönelik Tutum Ölçeği’nin Türkçe’ye Uyarlanması, Geçerlik Ve Güvenirliğinin İncelenmesi. [yüksek lisans tezi] İzmir, Türkiye: Hemşirelik Esasları Anabilim Dalı, Ege Üniversitesi Sağlık Bilimleri Enstitüsü;2013.

14.Kaddourah B, Shaheen A, Al-Tannir M. Knowledge and attitutes of health professionals towards pressure ulcers at a rehabilitation hospital. BMC Nursing. 2016;15:17-22.

15. Beeckman D, Defloor T, Schoomhoven L, Vanderwee K. Knowledge and attitudes of nurses on pressure ulcer prevention: a cross- sectional multicenter study in belgian hospitals. Worldviews on Evidence Based Nursing. 2011;8(3):166-76.

16.Demarré L, Vanderwee K, Defloor T, Verhaeghe S, Schoonhoven L, Beeckman D. Pressure ulcers: knowledge and attitude of nurses and nursing assistants in Belgian nursing homes. Journal of Clinical Nursing. 2012(10):1425-34.

17.Ünver S, Yıldız Fındık Ü, Kızılcık Özkan Z, Sürücü Ç. Attitudes of surgical nurses towards pressure ulcer prevention. Journal of Tissue Viability. 2017;26:277-281.

18. Usher K, Woods C, Brown J, et al. Australian nursing students' knowledge and attitudes towards pressure injury prevention: a cross-sectional study. International Journal of Nursing Studies. 2018;81:14-20.

19.Simonetti V, Comparcini D, Flacco ME, Di Giovanni P. Nursing students' knowledge and attitude on pressure ulcer prevention evidence-based guidelines: a multicenter cross-sectional study. Nurse Education Today. 2015;35:573-579. 
20. Athlin E, Idvall E, Jernfält M, Johansson I. Factors of importance to the development of pressure ulcers in the care trajectory: perceptions of hospital and community care nurses. Journal of Clinical Nursing. 2009;19:2252-2258.

21.McCluskey A, Lovarini M. Providing education on evidence-based practice improved knowledge but did not change behaviour: a before and after study. $B M C$ Med Educ. 2005;5(40):5-12.

22. Gunningberg L. Pressure ulcer prevention: evaluation of an education programme for swedish nurses. $J$ Wound Care. 2004;13(3):85-9.

23. Kalman U, Suserud B. Knowledge, attitudes and practice among nursing staff concerning pressure ulcer prevention and treatment - a survey in a Swedish healthcare setting. Scandinavian Journal of Caring Sciences. 2009;23:334-341.

24. Strand T, Lindgren M. Knowledge, attitudes and barriers towards prevention of pressure ulcers in intensive care units: a descriptive cross-sectional study. Intensive and Critical Care Nursing. 2010;26:335-342. 